\title{
Impact of Kiln Drying Schedule upon Some Mechanical Properties of Poplar Wood
}

\author{
Hadi DASHTI ${ }^{1}$, Mahdi SHAHVERDI ${ }^{\circ}$, Seyed Ali HAJI MIRZA TAYEB ${ }^{2}$, Hossein LOTFIZADEH ${ }^{3}$ \\ ${ }^{1}$ University of Tehran, Faculty of Natural Resources, Department of Wood and Paper Science and \\ Technology, Karaj, Iran; m_shahverdi@ut.ac.ir ( ${ }^{*}$ corresponding author) \\ ${ }^{2}$ Islamic Azad University, Karaj Branch, Department of Wood Science and Technology, Karaj, Iran \\ ${ }^{3}$ Islamic Azad University, Karaj Branch, Department of Mechanical Engineering, Karaj, Iran
}

\begin{abstract}
In the present research, the effect of three kiln drying schedules of $\mathrm{T}_{5}-\mathrm{D}_{2}, \mathrm{~T}_{5}-\mathrm{D}_{4}$, and $\mathrm{T}_{5}-\mathrm{D}_{6}$ on poplar wood mechanical properties was investigated. The lumber was dried in a convectional laboratory kiln and then the compression strength in a parallel and perpendicular direction toward the grain, hardness, and nail withdrawal resistance were evaluated. The obtained results indicated with change from schedule $\mathrm{T}_{5}-\mathrm{D}_{2}$ to $\mathrm{T}_{5}-\mathrm{D}_{4}$, compression strength whether parallel or perpendicular to grain, hardness in tangential, radial, and transverse surfaces as well as, nail withdrawal resistance in tangential, radial, and transverse surfaces increased up to 18.1, 7.1, 16.4, 19.7, 14.1, 19.8, 5.7, and $9.2 \%$ respectively, as against schedule $T_{5}-D_{2}$. Despite $T_{5}-D_{4}$ schedule, compression strength parallel to grain dropped in specimens dried by schedule $\mathrm{T}_{5}-\mathrm{D}_{6}$. However, nail withdrawal resistance of specimens dried by $\mathrm{T}_{5}-\mathrm{D}_{6}$ schedule was higher in all the three surfaces than the two other schedules. As regards, the $\mathrm{T}_{5}-\mathrm{D}_{6}$ schedule, compression strength perpendicular to grain and also hardness in all the three surfaces rose as opposed to that of $\mathrm{T}_{5}-\mathrm{D}_{2}$ schedule, but showed a decrease in comparison to the corresponding figure in $\mathrm{T}_{5}-\mathrm{D}_{4}$. Moreover, statistical analysis revealed that except the compression strength perpendicular to grain, other mechanical strength inducing by various wood drying conditions were put in separate statistical groups.
\end{abstract}

Keywords: compression strength, hardness, nail withdrawal resistance, poplar, wood drying

\section{Introduction}

In wood drying process, various schedules are used to dry lumber, and the change in these schedules is made for different purposes. The main goals of wood drying programs may include reducing the energy consumption, increasing drying rate, acquiring better quality, and finally for minimizing the drying costs (Korkut and Guller, 2007).

Numerous researches have been carried out toward investigation of probable effects of various drying conditions on mechanical properties of dried woods. Most of these studies have been conducted at temperatures above $100^{\circ} \mathrm{C}$ (Gerhards, 1979; Oltean, 2007; Salamon, 1969; Schneider, 1973; Thiam et al., 2002). However, researches regarding evaluation of mechanical properties below $100^{\circ} \mathrm{C}$ (Oltean et al., 2011; Shahverdi et al., 2012b; Teischinger 1992) are scarce. There are various influential parameters on mechanical characteristics of the dried woods, such as moisture loss, applied temperature, residual stress and strain (Thiam et al., 2002), and crack occurrence (Oltean et al., 2007). Oltean et al. (2011) studied the influence of four different temperatures $\left(45,55,65\right.$ and $80^{\circ} \mathrm{C}$ ) on the mechanical properties of dried boards including threepoint ending test, impact ending test, and tensile test perpendicular to the grain. They stated that the mechanical properties investigated were not influenced by the drying temperatures applied. Teischinger (1992) observed that the modulus of rupture (MOR) and modulus of elasticity (MOE) of spruce wood changed little with respect to drying temperature. In a further research, Shahverdi et al. (2012b) studied some mechanical properties of poplar wood, such as MOE, MOR, toughness, shear strength parallel to grain, as well as, tensile strength perpendicular to grain, under three various drying schedules. In contrast to toughness and tensile strength perpendicular to grain, the shear strength parallel to grain, MOE, and MOR of dried lumber were affected by the drying schedule. The MOE and MOR decreased significantly by intensifying the drying schedule.

In moisture-based schedules, the raise in the dry-bulb temperature is one of the most common methods to expedite the wood drying procedure. Another method which is used less frequently, is to increase the wet-bulb depression. By this method, in fact, without any increase in dry-bulb temperature which contributes to higher drying costs, drying rate could be improved by reducing the kiln relative humidity. Shahverdi et al. (2012a) demonstrated that a rise in wet-bulb depression would result in an increased drying rate of poplar wood. 
Given the using of low relative humidity in the kiln, study of mechanical properties of dried woods is of high value, though its influence has not been clarified yet. Hence, this research aims to better understanding the effects of three different schedules of $T_{5}-D_{2}, T_{5}-D_{4}$, and $T_{5}$ $\mathrm{D}_{6}$ on some mechanical properties of poplar wood.

\section{Materials and methods}

\section{Sampling}

Freshly-cut logs of poplar (Populus alba L.) with approximately $17-20$ years of growth and $30-35 \mathrm{~cm}$ diameter, belonging to a forest close to the Taleghan region in Iran were selected for the study. Sample lumber pieces were cut in the tangential direction to produce uniform blocks with a nominal thickness of $7 \mathrm{~cm}$, a length of 220 $\mathrm{cm}$, and a width of $14 \mathrm{~cm}$ at a private sawmill. The number of boards in each of the three charges was 30 boards. Then, immediately, their cross sections were completely coated with oil-based paint in order to prevent moisture loss and occurrence of local cracks.

A $3 \mathrm{~m}^{3}$ capacity semi-automatic kiln with convective drying method was used. The kiln stack was $1 \mathrm{~m}$ wide. Furthermore, $2.5 \times 2.5 \mathrm{~cm}^{2}$ stickers from the same species were used in this study. All the boards were dried up to approximately $7-10 \%$. Three different programs were used for drying. The course of changes in the programs was as follows: Program 1-The proposed code of Forest Products

Tab. 1. $\mathrm{T}_{5}-\mathrm{D}_{2}$ kiln drying schedule for $P$. alba lumber with $7 \mathrm{~cm}$ thickness

\begin{tabular}{cccccc}
\hline $\begin{array}{c}\text { Moisture } \\
\text { content }(\%)\end{array}$ & $\begin{array}{c}\text { Wet bulb } \\
\text { temperature }\left({ }^{\circ} \mathrm{C}\right)\end{array}$ & $\begin{array}{c}\text { Dry bulb } \\
\text { temperature }\left({ }^{\circ} \mathrm{C}\right)\end{array}$ & $\begin{array}{c}\text { Wet bulb } \\
\text { depression }\left({ }^{\circ} \mathrm{C}\right)\end{array}$ & $\begin{array}{c}\text { Relative } \\
\text { humidity }(\%)\end{array}$ & $\begin{array}{c}\text { Equilibrium } \\
\text { moisture content }(\%)\end{array}$ \\
\hline $\mathrm{MC}>50$ & 47 & 49 & 2 & 90 & 20.9 \\
50 & 46 & 49 & 3 & 85 & 79 \\
40 & 45 & 49 & 4 & 61 & 16.4 \\
35 & 41 & 49 & 17 & 31 & 11.4 \\
30 & 37 & 64 & 28 & 10 & 6.5 \\
25 & 32 & 65 & 28 & 6 & 2.5 \\
20 & 37 & 71 & 28 & 24 & 1.6 \\
12 & 43 & 71 & 28 & 24 & 5.2 \\
\hline Equalization & 43 & & & 5.2 \\
\hline
\end{tabular}

Tab. 2. $\mathrm{T}_{5}-\mathrm{D}_{4}$ kiln drying schedule for $P$. alba lumber with $7 \mathrm{~cm}$ thickness

\begin{tabular}{cccccc}
\hline $\begin{array}{c}\text { Moisture } \\
\text { content }(\%)\end{array}$ & $\begin{array}{c}\text { Wet bulb } \\
\text { temperature }\left({ }^{\circ} \mathrm{C}\right)\end{array}$ & $\begin{array}{c}\text { Dry bulb } \\
\text { temperature }\left({ }^{\circ} \mathrm{C}\right)\end{array}$ & $\begin{array}{c}\text { Wet bulb } \\
\text { depression }\left({ }^{\circ} \mathrm{C}\right)\end{array}$ & $\begin{array}{c}\text { Relative } \\
\text { humidity }(\%)\end{array}$ & $\begin{array}{c}\text { Equilibrium } \\
\text { moisture content }(\%)\end{array}$ \\
\hline MC $>50$ & 45 & 49 & 4 & 79 & 16 \\
50 & 44 & 49 & 5 & 74 & 14.5 \\
40 & 41 & 49 & 14 & 31 & 11.4 \\
35 & 35 & 49 & 22 & 17 & 7.6 \\
30 & 32 & 54 & 28 & 10 & 4 \\
25 & 32 & 60 & 28 & 6 & 2.5 \\
20 & 37 & 65 & 28 & 24 & 1.6 \\
15 & 43 & 71 & 28 & 24 & 5.2 \\
12 & 43 & 71 & 28 & 24 & 5.2 \\
\hline Equalization & 43 & & & 5.2 \\
\hline
\end{tabular}

Tab. 3. $\mathrm{T}_{5}-\mathrm{D}_{6}$ kiln drying schedule for $P$. alba lumber with $7 \mathrm{~cm}$ thickness

\begin{tabular}{cccccc}
\hline $\begin{array}{c}\text { Moisture } \\
\text { content }(\%)\end{array}$ & $\begin{array}{c}\text { Wet bulb } \\
\text { temperature }\left({ }^{\circ} \mathrm{C}\right)\end{array}$ & $\begin{array}{c}\text { Dry bulb } \\
\text { temperature }\left({ }^{\circ} \mathrm{C}\right)\end{array}$ & $\begin{array}{c}\text { Wet bulb } \\
\text { depression }\left({ }^{\circ} \mathrm{C}\right)\end{array}$ & $\begin{array}{c}\text { Relative } \\
\text { humidity }(\%)\end{array}$ & $\begin{array}{c}\text { Equilibrium } \\
\text { moisture content }(\%)\end{array}$ \\
\hline $\mathrm{MC}>50$ & 41 & 49 & 8 & 61 & 11.4 \\
50 & 38 & 49 & 11 & 48 & 9.1 \\
40 & 32 & 49 & 17 & 29 & 6.1 \\
35 & 21 & 49 & 28 & 5 & 0.6 \\
30 & 26 & 54 & 28 & 10 & 1.4 \\
\hline 25 & 32 & 60 & 28 & 6 & 2.5 \\
20 & 37 & 71 & 28 & 24 & 5.6 \\
15 & 43 & 71 & 28 & 24 & 5.2 \\
12 & 43 & 71 & 28 & 24 & 5.2 \\
\hline
\end{tabular}


160

Laboratory (F.P.L) $\left(\mathrm{T}_{5}-\mathrm{D}_{2}\right)$; Program 2-a higher wet bulb depression was selected $\left(\mathrm{T}_{5}-\mathrm{D}_{4}\right)$; and Program 3-wet bulb depression was again increased $\left(\mathrm{T}_{5}-\mathrm{D}_{6}\right)($ Tab. 1-3).

\section{Mechanical tests}

To carry out the mechanical tests, the test samples were cut according to D143-94R ASTM standard. Before mechanical tests, the prepared samples were stored at a temperature of $20 \pm 1^{\circ} \mathrm{C}$ and relative humidity of $65 \pm 5 \%$ inside a climatic chamber for two weeks. The mechanical properties of the samples, including compression strength parallel and perpendicular to grain, hardness, and nail withdrawal resistance were measured using an INSTRON testing machine of IX series (Model 4486).

\section{Statistical analysis}

Statistical analysis was conducted using SPSS software program, version 13. One way ANOVA was performed to conclude significant difference at $95 \%$ confidence level. Grouping was then made between treatments using the Duncan's multiple range test.

\section{Results and discussion}

Considering that this article is the final phase of a research project, general review of the obtained results in former research is crucial (Shahverdi et al. 2012a, 2012b). Shahverdi et al. (2012a) mentioned that the drying rate in schedules of $\mathrm{T}_{5}-\mathrm{D}_{2}, \mathrm{~T}_{5}-\mathrm{D}_{4}$, and $\mathrm{T}_{5}-\mathrm{D}_{6}$ are $0.09,0.08$, and $0.21 \% / \mathrm{h}$, respectively. Given the increased wet-bulb depression in schedule $\mathrm{T}_{5}-\mathrm{D}_{4}$ as against $\mathrm{T}_{5}-\mathrm{D}_{2}$, drying rate did not undertake a significant difference. In schedule $\mathrm{T}_{5}-\mathrm{D}_{6}$, however, the corresponding figure was almost as twice as the other two schedules. The intensity of internal stresses in schedules $T_{5}-D_{2}$ and $T_{5}-D_{4}$ did not show a significant difference, while in schedule $\mathrm{T}_{5}-\mathrm{D}_{6}$, the figure was significantly increased in comparison to the other two schedules. Besides, the extent of superficial cracks did not differ much in the three used schedules, at the same time

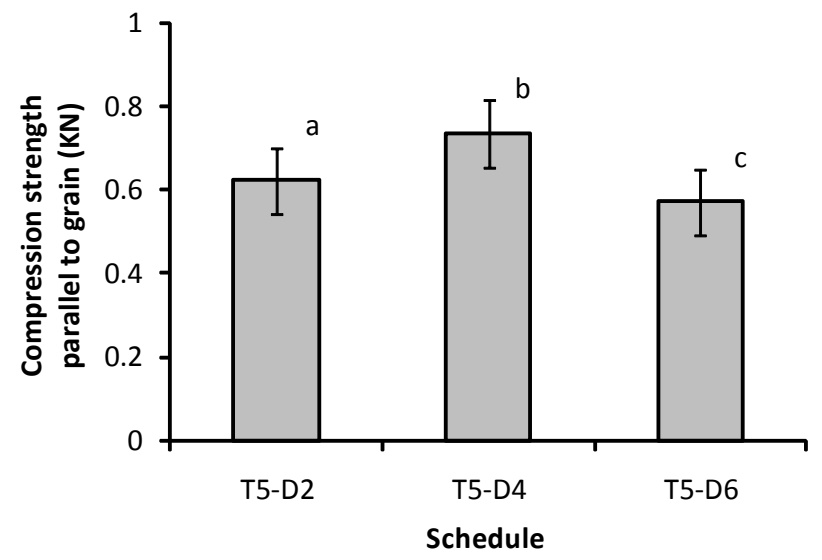

Fig. 1. Compression strength parallel to grain in the dried woods under the three adopted schedules a significant increase was observed concerning internal cracks in schedule $\mathrm{T}_{5}-\mathrm{D}_{6}$ compared to $\mathrm{T}_{5}-\mathrm{D}_{2}$.

In another research, Shahverdi et al. (2012b) investigated MOE, MOR, toughness, shear strength parallel to grain, and tensile strength perpendicular to grain of poplar lumber dried by different schedules. In comparison to $T_{5}$. $\mathrm{D}_{2}$ schedule, MOR in $\mathrm{T}_{5}-\mathrm{D}_{4}$ and $\mathrm{T}_{5}-\mathrm{D}_{6}$, likewise MOE, showed an increase and a decrease respectively. There was no statistically noticeable difference regarding toughness and tension strength perpendicular to grain among all the three adopted schedules. Shear strength parallel to grain was higher in schedule $\mathrm{T}_{5}-\mathrm{D}_{4}$ than other two schedules.

\section{Compression strength}

As it can be detected in Fig. 1, the amount of compression strength parallel to grain in schedules $\mathrm{T}_{5}-\mathrm{D}_{2}, \mathrm{~T}_{5}-\mathrm{D}_{4}$, and $\mathrm{T}_{5}-\mathrm{D}_{6}$ were $0.62,0.73$ and $0.57 \mathrm{KN}$, respectively. Statistical analysis indicated that all the three schedules are placed in three distinct groups. The degree of compression strength parallel to grain in $\mathrm{T}_{5}-\mathrm{D}_{4}$ schedule increased by $18.1 \%$ as opposed to $\mathrm{T}_{5}-\mathrm{D}_{2}$, whereas in schedule $\mathrm{T}_{5}-\mathrm{D}_{6}$ it declined by $8.2 \%$. In schedule $T_{5}-D_{6}$, the intensity of occurrence of internal cracks was greater than that of the two other schedules (Shahverdi et al., 2012a). Given that the compression strength parallel to grain greatly depends on the existing internal cracks in wood, it was supposed that due to occurrence of severe internal cracks in schedule $T_{5}$ $\mathrm{D}_{6}$, there should be a noticeable depression in this schedule toward other two schedules. Moreover, the severity of warping was more in schedule $\mathrm{T}_{5}-\mathrm{D}_{6}$ than the others (Shahverdi et al., 2012a). Increased warping, particularly in schedule $\mathrm{T}_{5}-\mathrm{D}_{6}$, causes a distraction in orthotropic structure of dried woods and therefore fibers surface to be disturbed. Consequently, it would lead to confusion in stress relieving pattern and eventually reduces the mechanical properties.

Shahverdi et al. (2012b) also showed that MOR and MOE in schedule $T_{5}-D_{6}$, in contrast to $T_{5}-D_{2}, T_{5}-D_{4}$, decreased. The amount of compression strength perpendicu-

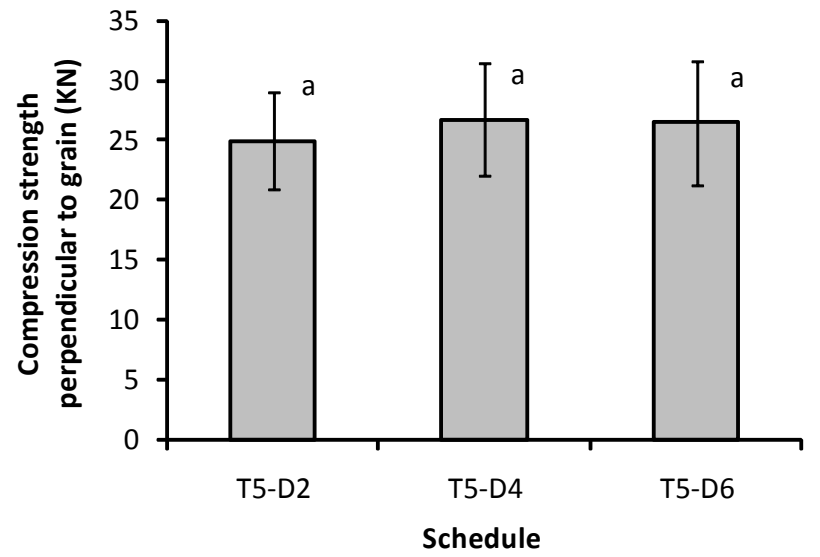

Fig. 2. Compression strength perpendicular to grain in the dried woods under the three adopted schedules 
lar to grain in specimens dried under schedules $\mathrm{T}_{5}-\mathrm{D}_{2}, \mathrm{~T}_{5}$ $\mathrm{D}_{4}$, and $\mathrm{T}_{5}-\mathrm{D}_{6}$ were $24.9,26.7$ and $26.4 \mathrm{KN}$ respectively (Fig. 2). Despite the existing differences between the mean values, the statistical analysis suggests that there is no significant difference between the adopted schedules. For the sake of a dearth of high dependency of internal cracks to compression strength perpendicular to grain, probably no significant difference was observed between the obtained data. However, given that the drying rate in schedule $T_{5}$ $\mathrm{D}_{6}$ has been higher than other two schedules, and it could be stated that the drying rate could not have negative influence on this strength.

\section{Hardness and nail withdrawal resistance}

Hardness is a practical mechanical property used to assess the suitability of a wood species for use as residential and/or commercial flooring (Wiemann and Green, 2007). The hardness results in tangential, radial, and transverse surfaces are provided in Fig. 3. The hardness in tangential surface was higher than the radial one which is consistent with the results obtained by Poncsak et al. (2006). Furthermore, the results indicate that the hardness in tangential surface in two schedules of $\mathrm{T}_{5}-\mathrm{D}_{4}$ and $\mathrm{T}_{5}-\mathrm{D}_{6}$, in comparison with $\mathrm{T}_{5}-\mathrm{D}_{2}$, has been increased by 16.4 and $14.8 \%$, respectively. Although the dried specimens by the former schedule had greater hardness than that of $\mathrm{T}_{5}-\mathrm{D}_{6}$, from the statistical point of view, both are placed in a similar group,

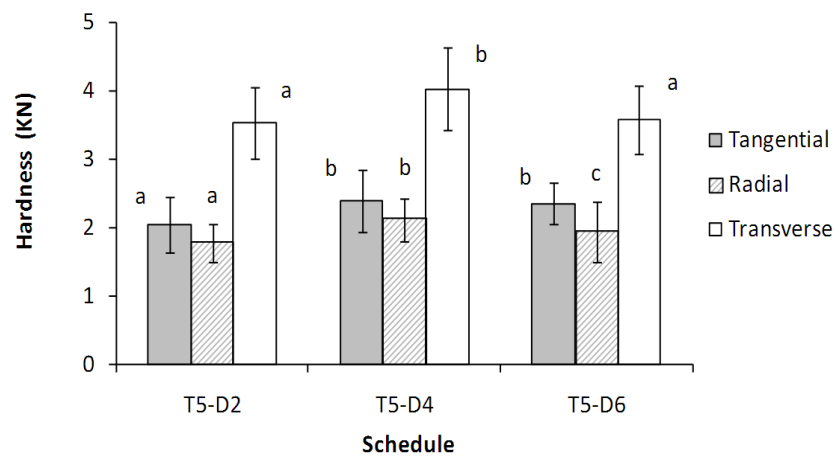

Fig. 3. Hardness in tangential, radial, and transverse surfaces of samples dried under the three adopted kiln schedules

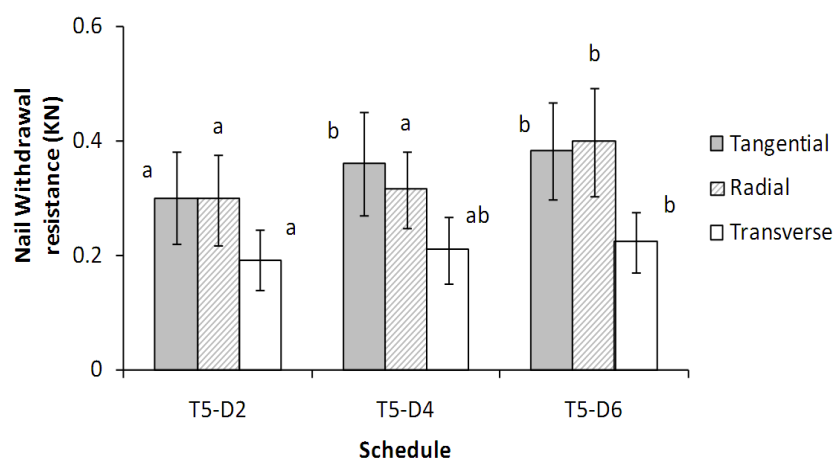

Fig. 4. Nail withdrawal resistance in tangential, radial, and transverse surfaces of samples dried under the three adopted kiln schedules whereas $\mathrm{T}_{5}-\mathrm{D}_{2}$ is placed in another one. The hardness in radial surface was also increased more in schedules $\mathrm{T}_{5}$ $\mathrm{D}_{4}$ and $\mathrm{T}_{5}-\mathrm{D}_{6}$ than $\mathrm{T}_{5}-\mathrm{D}_{2}$, by 19.7 and $9.6 \%$ respectively. Meanwhile, they were statistically placed in three distinct groups. The hardness in transverse surface of woods dried by $\mathrm{T}_{5}-\mathrm{D}_{4}$ and $\mathrm{T}_{5}-\mathrm{D}_{6}$ schedules, in contrast to $\mathrm{T}_{5}-\mathrm{D}_{2}$, experienced an increase of 14.1 and $1.4 \%$ respectively. Statistically, the woods dried using schedule $\mathrm{T}_{5}-\mathrm{D}_{4}$ were put in one group and the two other schedules in another one.

As the results indicate, in $\mathrm{T}_{5}-\mathrm{D}_{4}$ schedule the hardness was higher in tangential, radial, and transverse surfaces than that of $\mathrm{T}_{5}-\mathrm{D}_{6}$ and also the $\mathrm{T}_{5}-\mathrm{D}_{6}$ was greater than $\mathrm{T}_{5}$ $\mathrm{D}_{2}$. The reduction of hardness in various surfaces in woods dried by $\mathrm{T}_{5}-\mathrm{D}_{6}$ schedule as against schedule $\mathrm{T}_{5}-\mathrm{D}_{4}$, might be due to the residual stresses in these specimens induced by low relative humidity in the procedure of this schedule. Given that the groupings in various surfaces have been different and no particular research has been carried out on this issue at low temperatures, statistically no specific conclusion could be drawn regarding the probable effects of increased wet-bulb depression on hardness in various surfaces. Considering that the hardness in various surfaces is under influence of the wood density and density itself also differs in different points of wood, the occurred changes in hardness in various surfaces and different schedules could not only be the result of drying conditions. As regards, further studies are required for better understanding of influential factors on this mechanical property. On the other side, some studies have indicated that hardness is not affected by drying conditions. Bustos et al. (2009) in a research on tamarack wood suggested that hardness is influenced by density; and drying conditions and drying temperature have no effect on it. Hansson and Antti (2006) state that hardness rather than being influenced by drying method is affected by wood density and moisture content.

In Fig. 4, the results of nail withdrawal resistance test in tangential, radial, and transverse surfaces are presented. Nail withdrawal resistance in tangential surface in schedules $\mathrm{T}_{5}-\mathrm{D}_{4}$ and $\mathrm{T}_{5}-\mathrm{D}_{6}$ increased by 19.8 and $27.6 \%$ as opposed to $T_{5}-D_{2}$. Nail withdrawal resistance in transverse direction is less than the corresponding figure in tangential and radial directions, which is in accordance with results obtained by Aytekin (2008). From the statistical point of view, nail withdrawal resistance in tangential surface of $\mathrm{T}_{5}$. $\mathrm{D}_{2}$ schedule was placed in one group, and the woods dried by the other two schedules are put in a separate group. Additionally, nail withdrawal resistance in radial surface of wood dried by schedules $\mathrm{T}_{5}-\mathrm{D}_{4}$ and $\mathrm{T}_{5}-\mathrm{D}_{6}$ rose by 5.7 and $33.6 \%$, relatively, compared to that of schedule $\mathrm{T}_{5}-\mathrm{D}_{2}$. The schedule $\mathrm{T}_{5}-\mathrm{D}_{6}$ is placed in one group and the other two programs in a distinct group. Besides, nail withdrawal resistance in transverse surface of specimens dried under schedules $\mathrm{T}_{5}-\mathrm{D}_{4}$ and $\mathrm{T}_{5}-\mathrm{D}_{6}$ rose by 9 and $16.5 \%$, relatively, as against that of schedule $\mathrm{T}_{5}-\mathrm{D}_{2}$. Statistically, the results revealed that regarding nail withdrawal resistance in trans- 
162

verse surface of woods dried by schedules $\mathrm{T}_{5}-\mathrm{D}_{2}$ and $\mathrm{T}_{5}-\mathrm{D}_{6}$ is placed into two different groups and that in schedule $\mathrm{T}_{5}-\mathrm{D}_{4}$ is put in both ones.

Results denoted that the increasing rate in nail withdrawal resistance in all the three surfaces of woods in schedule $T_{5}-D_{6}$ was greater than that in schedule $T_{5}-D_{4}$ Whereas in the hardness test, the greatest increase in all three surfaces was observed in schedule $\mathrm{T}_{5}-\mathrm{D}_{4}$. Noguchi and Sugihara (1961) stated that nail withdrawal resistance in tangential surface is greater than all the other surfaces, and this resistance is associated to the wood density and the nail diameter. In general, given the obtained results, it could be concluded that with increasing the drying rate, nail withdrawal resistance would be increased. Perhaps due to the increased drying rate in the woods dried by schedule $\mathrm{T}_{5}-\mathrm{D}_{6}$, compared to other two ones, and intensity of warping and consequently disturbance in the fibers direction, nail withdrawal resistance in this schedule has increased.

\section{Conclusions}

In this research the influence of different convectional drying conditions upon some mechanical properties of dried woods was investigated. Results revealed that compression strength parallel to grain as well as perpendicular to grain, hardness and nail withdrawal resistance in all the three surfaces increased from $T_{5}-D_{2}$ to $T_{5}-D_{4}$ schedule. Regardless of compression strength parallel to grain, with increasing of severity in drying schedule from $T_{5}-D_{2}$ to $T_{5}$ $\mathrm{D}_{6}$; or with increasing of the wet-bulb depression almost all the mechanical properties were climbed. According to drying intensity, each of the studied strengths changed by varying degrees. In general, it could be mentioned that speeding up the drying process by increasing of wet-bulb depression not only would be economically beneficial (i.e. by decreasing the drying costs), but it could improve some mechanical characteristics of the dried woods as well.

\section{References}

Aytekin A (2008). Determination of screw and nail withdrawal resistance of some important wood species. Int J Mol Sci 9:626-637.

Bustos C, Hernandez RE, Fortin Y (2009). Effect of kiln-drying on the hardness and machining properties of tamarack wood for flooring. Forest Prod J 59(1-2):71-76.

Gerhards CC (1979). Effect of high temperature drying on tensile strength of Douglas fir 2 by 4's. Forest Prod J 29(3):39-46.
Hansson L, Antti L (2006). The effect of drying method and temperature level on the hardness of wood. J Mater Proces Technol 171(3):467-470.

Korkut S, Guller B (2007). Comparison of two drying schedules for European Hophornbeam (Ostrya carpinifolia Scop.) lumber. Drying Technol 25(12):1977-1984.

Noguchi M, Sugihara H (1961). Studies on static withdrawal resistance of nail. effect of driving method and time after driving. Wood Res 25:1-13.

Oltean L, Teischinger A, Hansmann C (2007). Influence of temperature on cracking and mechanical properties of wood during wood drying. A review. BioResources 2(4):789-811.

Oltean L, Teischinger A, Hansmann C (2011). Influence of low and moderate temperature kiln drying schedules on specific mechanical properties of Norway spruce wood. Eur J Wood Prod 69:451-457.

Poncsak S, Kocaefe D, Bouazara M, Pichette A (2006). Effect of high temperature treatment on the mechanical properties of birch (Betula papyrifera). Wood Sci Technol 40:647-663.

Salamon M (1969). High temperature and its effect on wood properties. Forest Prod J 19(3):27-34.

Schneider A (1973). Investigations on the convection drying of lumber at extremely high temperatures Part 2: Drying degrade, changes in sorption, colour and strength of pine sapwood and beech wood at drying temperatures from 110 to $180^{\circ} \mathrm{C}$. Holz Roh Werkstoff 31(5):198-206.

Shahverdi M, Dashti H, Hossein MA (2012a). Establishing A kiln drying schedule for poplar (Populus alba L.) lumber of $7 \mathrm{~cm}$ thickness. BioResources 7(1):26-37.

Shahverdi M, Tarmian A, Dashti H, Ebrahimi G, Tajvidi M (2012b). Mechanical properties of poplar wood (Populus alba) dried by three kiln drying schedules. BioResources 7(1):1092-1099.

Teischinger A (1992). Effect of different drying temperatures on selected physical wood properties, 211-216 p. In: Proc of $3^{\text {rd }}$ IUFRO Int. Wood Drying Conference, Vienna.

Thiam M, Milota M.R, and Leichti R (2002). Effect of hightemperature drying on bending and shear strengths of western hemlock lumber. Forest Prod J 52(4):64-68.

Wiemann MC, Green DW (2007). Estimating Janka hardness from specific gravity for tropical and temperate species. RPFPL-643. USDA Forest Serv, Forest Products Lab, Madison, Wisconsin, $21 \mathrm{p}$. 